\title{
The genotoxicity of an aqueous extract of Gyejibokryeong-hwan
}

\author{
Mee-Young Lee', Chang-Seob Seo ${ }^{1}$, Hyekyung Ha', Eunsook Park', Ji-Young Kim² and Hyeun-Kyoo Shin ${ }^{1 *}$
}

\begin{abstract}
Background: Gyejibokryeong-hwan (Guizhi Fuling Wan in China), a mixture of five herbal plants, is a well-known treatment for renal diseases including those associated with climacteric syndrome. However, the genotoxicity of Gyejibokryeong-hwan has not yet been well established.

Methods: The present study investigated that the genotoxicity of an aqueous extract of Gyejibokryeong-hwan (GJBRHE): an in vitro chromosomal aberration test using Chinese hamster lung cells, an in vitro bacterial reverse mutation assay (Ames test) with Salmonella typhimurium and Escherichia coli strains, and an in vivo micronucleus test using ICR mouse bone marrow.

Results: GJBRHE with or without the 59 mix showed no genotoxicity in the Ames test up to $5000 \mu \mathrm{g} /$ plate or in the in vivo MN test up to $2000 \mathrm{mg} / \mathrm{kg}$ body weight. In contrast, the chromosomal aberration test showed that GJBRHE induced an increase in the number of chromosomal aberrations compared with the control after treatment for $6 \mathrm{~h}$ with $4200 \mu \mathrm{g} / \mathrm{mL}$ GJBRHE in the presence of the $\$ 9$ mix and for $22 \mathrm{~h}$ with $800 \mu \mathrm{g} / \mathrm{mL}$ GJBRHE in the absence of the 59 mix.

Conclusions: GJBRHE did not cause detectable genotoxic effects in the bacterial mutation test or the in vivo MN test, however genotoxic effect was detected in the in vitro chromosomal aberration assay. Our results suggest that GJBRHE may be associated with a low risk of carcinogenesis. Thus, further detailed experiments would be needed to clarify the compound responsible for inducing this genotoxicity of GJBRHE and to determine its mechanism.
\end{abstract}

Keywords: Gyejibokryeong-hwan, Ames test, Chromosome aberration assay, Micronucleus

\section{Background}

Many herbal medicines are widely used to be safety materials than other medicines $[1,2]$. The use of herbal products as first choice in primary supplements for improving health is popular [3]. Because people have become more interested in safety and in their well-being [4]. Recently, concerns have been raised the scientific evidence for the safety and efficacy of these herbal medicines $[5,6]$. However, the safety information of herbal medicines including oral toxicity, genotoxicity has been not yet enough. Among them, a genotoxicity test includes the hazard identification with regard to DNA damage and is required for the development of new drug [7].

Gyejibokryeong-hwan (Guizhi Fuling Wan in China and Keishi-bukuryo-gan in Japan) is a traditional Korean herbal

\footnotetext{
* Correspondence: hkshin@kiom.re.kr

${ }^{1}$ K-herb Research Center, Korea Institute of Oriental Medicine, 1672

Yuseongdae-ro, Yuseong-gu, Daejeon 305-811, Republic of Korea

Full list of author information is available at the end of the article
}

formula consist of five medicinal herbs: Cinnamomum ca ssia, Poria cocos, Oaeonia lactiflora, Paeonia suffruticosa, and Prunus persica. Gyejibokryeong-hwan has been used to treat climacteric symptoms caused by blood stasis and mass uterine disorders $[8,9]$. It has been reported that Gyejibokryeong-hwan exhibits biological and pharmacological activities against inflammation [10], cardiovascular diseases [11], diabetes [12], diabetic nephropathy [13], brain ischemia [14], and various cancers $[4,15]$. However, genotoxicity has not yet been studied. To ensure safety of the Gyejibokryeong-hwan, the current study performs genotoxicity assessment. The aim of a genotoxic assay is to detect carcinogens and other mutagens [16]. Therefore, the present study was aimed to determine the acute toxicity and genotoxic properties of an aqueous extract of Gyejibokryeong-hwan (GJBRHE) in assays including a bacterial reverse mutation (Ames) test, a chromosome aberration test, and an in vivo micronucleus (MN) test. 


\section{Methods}

\section{Chemicals and reagents}

Reference standards of amygdalin, coumarin, and cinnamic acid were purchased from Sigma-Aldrich (St. Louis, MO, USA). Albiflorin, cinnamaldehyde, paeoniflorin, and paeonol were obtained from Wako (Osaka, Japan). The purity of the seven reference standards was $\geq 98.0 \%$. The chemical structures of the seven marker components are shown in Fig. 1a. High-performance liquid chromatography (HPLC)-grade reagents methanol, acetonitrile, and water to obtain the aqueous extract of GJBRHE were obtained from J. T. Baker (Phillipsburg, NJ, USA). Acetic acid was purchased from Merck (Darmstadt, Germany).

\section{Plant materials}

The component herbs of Gyejibokryeong-hwan (Poria cocos, Paeonia suffruticosa, Cinnamomum cassia, Paeonia lactiflora, and Prunus persica) were purchased from Kwangmyungdag Medicinal Herbs (Ulsan, Korea) in
November 2013 and identified by Prof. Je Hyun Lee (Department of Herbology, College of Oriental Medicine, Dongguk University, Gyeongju, Korea). Voucher specimens (2013-KE31-1 to KE31-5) have been deposited at the K-herb Research Center, Korea Institute of Oriental Medicine (KIOM).

\section{Preparation of Gyejibokryeong-hwan decoction}

To obtain the Gyejibokryeong-hwan aqueous extract (GJBRHE), the five herbal medicines comprising Gyejibokryeong-hwan were mixed as shown in Table 1 (total weight $=125.0 \mathrm{~kg}$, equivalent to approximately 666.7 single doses), and extracted in a 10-fold mass of water $(1250 \mathrm{~L})$ at $100{ }^{\circ} \mathrm{C}$ for $2 \mathrm{~h}$. The aqueous extract was filtered by pressing through a filter $(10 \mu \mathrm{m}$ pore size), and then the solution was evaporated and freeze-dried to give a powder. The amount of Gyejibokryeong-hwan decoction powder was $15.7 \mathrm{~kg}$ (12.56\%). For HPLC analysis, $400 \mathrm{mg}$ of lyophilized Gyejibokryeong-hwan decoction powder was dissolved in $20 \mathrm{~mL}$ of distilled water and then

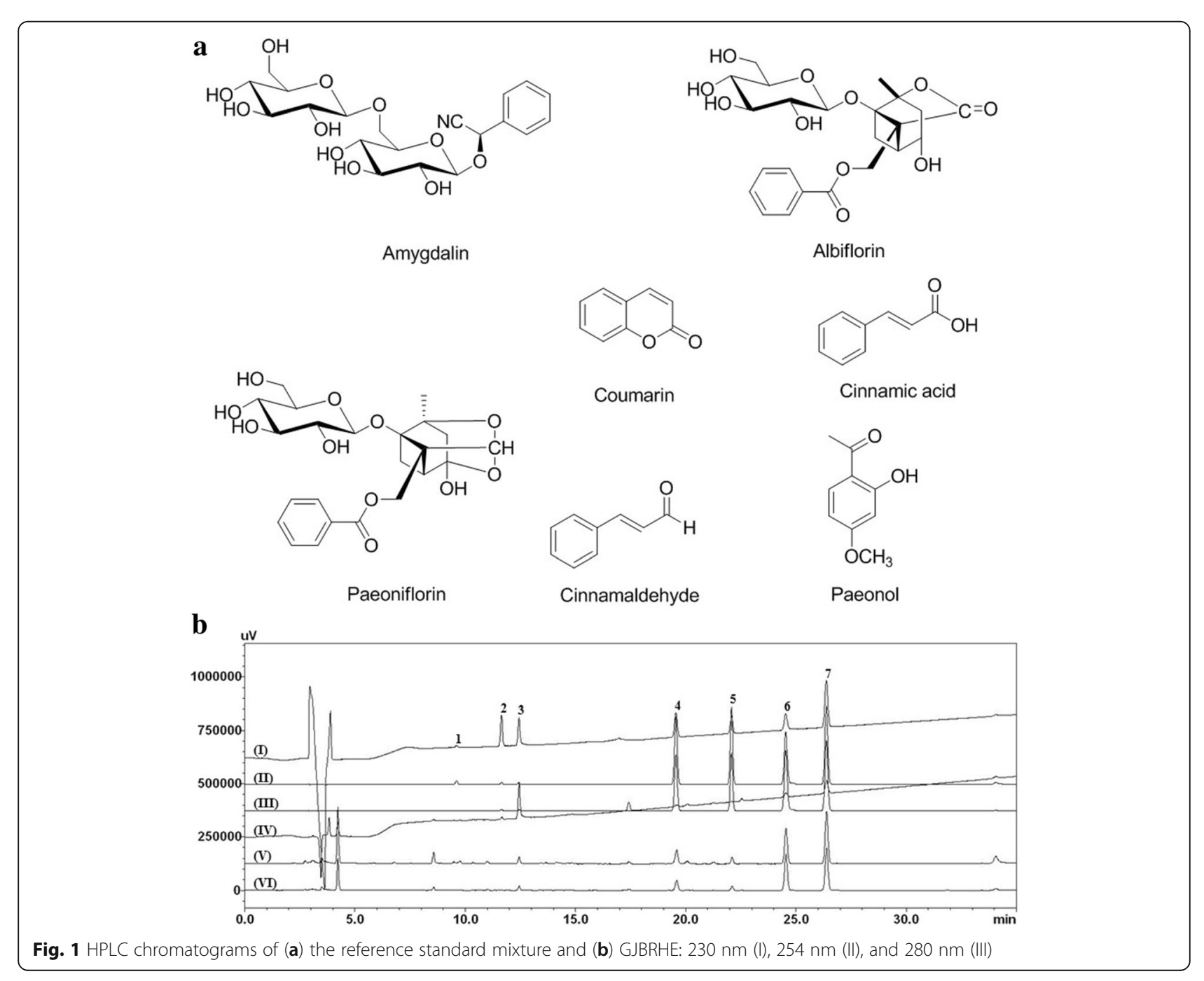


Table 1 The combination of crude components of Gyejibokryeong-hwan aqueous extract (GJBRHE)

\begin{tabular}{|c|c|c|c|c|c|}
\hline Herbal name & Scientific name & Family & Used parts & Original region & Amount $(\mathrm{g}$ \\
\hline Cinnamomi Ramulus & Cinnamomum cassia Presl & Lauraceae & Ramulus & Vietnam & 3.75 \\
\hline Hoelen & Poria cocos Wolf & Polyporaceae & Sclerotium & Pyeongchang, Korea & 3.75 \\
\hline Moutan Cortex Radicis & Paeonia suffruticosa Andrews & Paeoniaceae & Bark & Jecheon, Korea & 3.75 \\
\hline Paeoniae Radix & Paeonia lactiflora Pallas & Paeoniaceae & Root & Uiseong, Korea & 3.75 \\
\hline Persicae Semen & Prunus persica Batsch & Rosaceae & Seed & South Africa & 3.75 \\
\hline Total amount & & & & & 18.75 \\
\hline
\end{tabular}

extracted by sonication for $10 \mathrm{~min}$ on room temperature. The solution was filtered through a $0.2 \mu \mathrm{m}$ pore-size syringe filter (Woongki Science, Seoul, Korea) before HPLC injection.

\section{HPLC analysis of GJBRHE}

The chromatographic analysis for quantitative determination of the seven marker components in Gyejibokryeonghwan was performed using a Shimadzu Prominence LC20A system (Shimadzu Co., Kyoto, Japan) consisting of a solvent delivery unit, an on-line degasser, a column oven, a sample autoinjector, and a photodiode array (PDA) detector. The data were acquired and processed using LCsolution software (Version 1.24). The column used for separation of the seven constituents was a Phenomenex Gemini $\mathrm{C}_{18}$ column $(250 \times 4.6 \mathrm{~mm}, 5 \mu \mathrm{m}$, Torrance, CA, USA) maintained at $40{ }^{\circ} \mathrm{C}$. The mobile phases consisted of water (A) and acetonitrile (B), both containing 1.0\% ( $\mathrm{v} / \mathrm{v})$ acetic acid. The gradient elution of the mobile phase was as follows: $10-60 \% \mathrm{~B}$ for $0-30 \mathrm{~min}, 60-100 \% \mathrm{~B}$ for 30-40 $\mathrm{min}, 100 \% \mathrm{~B}$ for $40-45 \mathrm{~min}, 100-10 \% \mathrm{~B}$ for 45-50 min, and $100 \% \mathrm{~B}$ for $50-60 \mathrm{~min}$. The flow rate and injection volume were $1.0 \mathrm{~mL} / \mathrm{min}$ and $10 \mu \mathrm{L}$, respectively. The detection wavelengths for quantitative analysis of the seven compounds were set according to the maximum absorption wavelengths of each reference compound (amygdalin, albiflorin, paeoniflorin for P. persica, coumarin, cinnamic acid, cinnamaldehyde for C.cassia, paeonol for P.suffruticosa)..

\section{Acute oral toxicity study}

This study was approved by the Institutional Animal Care and Use Committee (IACUC) of Korea Institute of Toxicology (KIT; Daejeon, Korea); it was performed at KIT and was conducted according to the guidelines of the KIT IACUC (Number: G13088), which is accredited by the Association for Assessment and Accreditation of Laboratory Animal Care International (1998) under the Good Laboratory Practice Regulations for Nonclinical Laboratory Studies. Specific-pathogen-free Sprague Dawley rats (5 males and 5 females) were purchased from Orient Bio Co. (Seongnam, Korea). The acute oral toxicity study in rats was conducted as described previously [17]. Our preliminary study (N:P13030) showed that a single oral administration of GHBRHE did not induce any toxic effect at dose levels up to $5000 \mathrm{mg} / \mathrm{kg} /$ day (data not shown). Based on this study, a dose of $5000 \mathrm{mg} / \mathrm{kg} /$ day was selected as the experimental limit dose. GJBRHE was suspended in distilled water. The vehicle control rats received distilled water only. All animals were observed for 14 days and mortality, body weight changes, clinical signs, and gross findings were recorded. This study was conducted in accordance with the guidelines established by the FDA Good Laboratory Practice (GLP) for Nonclinical Laboratory Studies (21 CFR Part 58) and OECD guidelines [18].

\section{Ames test}

The used experimental methods were based on the report of Maron and Ames [19], with minor modifications. The Ames test was conducted as described previously [17]. Distilled water was selected as the vehicle based on the results of the solubility test and aseptic test. Various concentrations of GJBRHE were incubated with tester strains in the presence or absence of metabolic activation with the S9 mix along with vehicle. Each concentration of GJBRHE was assayed in triplicate. The present study was conducted in accordance with OECD guidelines for the Testing of Chemicals Section 4 Health Effects Test No. 471 about Bacterial Reverse Mutation Test (21 July 1997).

\section{Chromosome aberration test in Chinese hamster lung (CHL) cells}

Chromosome aberration tests were conducted as described previously [17] with minor modifications as described by Ishidate [20] and by Dean and Danford [21]. Chinese hamster lung (CHL) cells were selected as the test system because they are sensitive to mutagens, their low chromosome number facilitates scoring and the same cell line can be used repeatedly. Furthermore, because CHL cells are a widely used test system for in vitro mutagenicity studies, a broad historical database exists. The modal chromosome number of this cell line is 25 with a doubling time of $\sim 15-17 \mathrm{~h}$. The cells are thawed in culture medium and then grown for more than 7 days as a monolayer. Sterility was checked by inverted microscopy to determine any gross mycoplasma contamination and confirmed by polymerase chain 
reaction amplification. Cells were cultured in reconstituted modified Eagle's medium (Gibco-Invitrogen, Carlsbad, CA, USA) supplemented with $\mathrm{Na}_{2} \mathrm{HCO}_{3}$ (2.2 g), L-glutamine (292 mg), streptomycin sulfate $(100 \mu \mathrm{g})$, penicillin $\mathrm{G} \cdot \mathrm{Na}\left(10^{5}\right.$ units $)$ and $10 \%(v / \mathrm{v})$ fetal bovine serum (Gibco-Invitrogen) per liter. The cultures were incubated at $37{ }^{\circ} \mathrm{C}$ under humidified $1.5 \% \mathrm{CO}_{2}$ in air. Based on the results, the dose range for the present study was designed considering the solubility and cytotoxicity of SST. Ethyl methanesulfonate (EMS) was used as a positive control chemical without metabolic activation using the S9 mix, and cyclophosphamide (CPA) was used as a positive control with metabolic activation. The present study was conducted in accordance with OECD guidelines for the Testing of Chemicals Section 4 Health Effects Test No. 473 about In vitro Mammalian Chromosome Aberration Test (21 July 1997).

\section{In vivo $\mathrm{MN}$ test}

The MN test was performed as described by Muangphra and Gooneratne [22] with slight modifications. Bone marrow preparations were made according to the method described by Schmid [23]. MN tests using ICR male mice were conducted as described previously [17, 24]. The preliminary study showed that oral administration of GJBRHE did not induce any toxic effect at $2000 \mathrm{mg} / \mathrm{kg}$ (the dose limit for treatment up to 14 days according to OECD guidelines). This was selected as the maximum dose. Specific-pathogen-free male ICR strain mice weighing 27.2-30.0 g were obtained from Orient Co., Ltd. (Seongnam, Korea) at 6 weeks of age. According to Schmid [23] method, ICR mice were euthanized by $\mathrm{CO}_{2}$ gas after the final administration of GJBRHE and bone marrow preparations were made. Small round or oval bodies, measuring approximately $1 / 5$ to $1 / 20$ the diameter of a polychromatic erythrocyte (PCE), were counted as micronuclei. A total of 2000 PCEs were scored per animal to determine the frequency of MNPCEs and PCE/(PCE + NCE) ratio was calculated by counting 500 cells. Differences in the numbers of MNPCEs between treatment and control groups were analyzed using the Kruskal-Wallis $H$ test and Dunn's rank sum test. The Mann-Whitney nonparametric $U$ test was used to compare the $\mathrm{PCE} /(\mathrm{PCE}+\mathrm{NCE})$ ratios of treatment and control groups. Significance for all tests was accepted at $P<0.05$.

This study was approved by the Institutional Animal Care and Use Committee (IACUC) of Korea Institute of Toxicology (KIT; Daejeon, Korea); it was performed at KIT and was conducted according to the guidelines of the KIT IACUC (Number: N14005), which is accredited by the Association for Assessment and Accreditation of Laboratory Animal Care International (1998) under the
Good Laboratory Practice Regulations for Nonclinical Laboratory Studies.

\section{Statistical analyses}

Acute toxicity study, a one-way analysis of variance was performed at $\alpha=0.05$ in cases in which Bartlett's test indicated no significant deviations from variance homogeneity. When significance was noted, a multiplecomparison test (Dunnett's test) was used to determine which pairs of groups were significantly different. Statistical analyses were performed using the PATH/TOX system. Chromosome aberration assay, the statistical analyses were based on the methods used in the published reports [25] using Statistical Analysis System (SAS) software. Each metaphase was classified as a normal metaphase or an aberrant metaphase with one or more aberrations, and the frequency of aberrant metaphases was analyzed statistically. The $X^{2}$ test and Fisher's exact test [26] were performed to compare the vehicle control and GJBRHEtreated groups. The in vivo $\mathrm{MN}$ results were evaluated as described previously [27] using the method of Lovell et al. [28] with minor modifications. Data with heterogeneous variances were analyzed using Kruskal-Wallis analysis of variance followed by multiple comparisons using Dunnett's test [29]. The significance was accepted when all of the $\mathrm{PCE} /(\mathrm{PCE}+\mathrm{NCE})$ ratios were $>0.1$. The result was judged as positive when there was a significant and dose-related increase or a reproducible increase in the frequency of MNPCEs or aberrant metaphases at one or more dose levels. Differences were regarded as significant at $P<0.05$.

\section{Results}

Quantitative analysis of the seven marker compounds in Gyejibokryeong-hwan

The optimized HPLC-PDA method was used for quantitative determination of the seven marker compounds in the Gyejibokryeong-hwan sample. Using optimized chromatography conditions, all analytes separated in under 30 min; a typical HPLC chromatogram is shown in Fig. 1b. The wavelength of the PDA ranged from 190 to $400 \mathrm{~nm}$ and the detection wavelengths for quantitative analysis were $262 \mathrm{~nm}$ (amygdalin), $230 \mathrm{~nm}$ (albiflorin and paeoniflorin), and $280 \mathrm{~nm}$ (coumarin, cinnamic acid, cinnamaldehyde, and paeonol). The correlation coefficient $\left(r^{2}\right)$ of the five compounds showed good linearity of $\geq 0.9999$. The retention times of the seven components, coumarin, amygdalin, paeoniflorin, albiflorin, cinnamic acid, cinnamaldehyde, and paeonol were 9.60, 14.80, 15.55, 19.56, $22.08,24.53$, and $26.37 \mathrm{~min}$, respectively. The amounts of the seven marker compounds were $0.52-45.07 \mathrm{mg} / \mathrm{g}$ (Table 2). Among the compounds, paeoniflorin, the marker compound of $P$. lactiflora, was detected as the main component of GJBRHE at $45.07 \mathrm{mg} / \mathrm{g}$. This 
established HPLC-PDA method will be useful for improvement of the quality control of Gyejibokryeonghwan.

\section{Acute oral toxicity}

During the experimental period, no clinical symptoms or no mortality of toxicity were observed in rats of either sex in any of the GJBRHE-treated groups during the 14-day observation period. The changes in body weight are shown in Fig. 2. For both sexes, the changes in body weight did not differ significantly between the treated rats with $5000 \mathrm{mg} / \mathrm{kg} /$ day of GJBRHE and the control group. At the time of the scheduled autopsy, there were no abnormal pathological observations for the lung, thymus, heart, liver, stomach, adrenals, and spleen in the male or female rats given $5000 \mathrm{mg} / \mathrm{kg} /$ day of GJBRHE.

\section{Ames test}

No positive mutagenic response when compared with concurrent vehicle control groups was observed in any of the S. typhimurium TA1535, TA1573, TA100, and TA98 or E. coli WP2 uvrA strains at any dose level of GJBRHE regardless of the presence (Fig. 3a) or absence (Fig. 3b) of the S9 fraction at up to $5000 \mu \mathrm{g} /$ plate. There was a significant increase in all positive control groups (Fig. 3a and b).

\section{Chromosome aberration tests in CHL cells}

There were significant increases the frequency of metaphase cells with structural aberrations in cells treated for $6 \mathrm{~h}$ after S9 fraction with $4200 \mu \mathrm{g} / \mathrm{mL}$ GJBRHE in the presence of the $\mathrm{S} 9$ fraction and in those treated for $22 \mathrm{~h}$ S9 fraction with $800 \mu \mathrm{g} / \mathrm{mL}$ GJBRHE without the S9 fraction (Table 3 ). The positive controls showed significant increases in the frequency of metaphases (Table 3).

\section{In vivo $\mathrm{MN}$ test}

No clinical signs and no deaths of toxicity were observed in any of the GJBRHE treatment groups. As shown in Table 4, there was no significant change in body weight compared with the vehicle control between GJBRHE at

Table 2 Amounts of the seven marker compounds in the Gyejibokryeong-hwan aqueous extract by $\operatorname{HPLC}(n=3)$

\begin{tabular}{lllll}
\hline Compound & Mean $\left(\mathrm{mg} / \mathrm{g}^{*}\right)$ & SD $\times 10-1$ & RSD (\%) & Source \\
\hline Amygdalin & 12.51 & 2.13 & 1.71 & P. persica \\
Albiflorin & 2.29 & 0.21 & 0.94 & P. lactiflora \\
Paeoniflorin & 45.07 & 2.78 & 0.62 & P. lactiflora \\
Coumarin & 2.62 & 0.02 & 0.07 & C. cassia \\
Cinnamic acid & 0.52 & 0.01 & 0.26 & C. cassia \\
Cinnamaldehyde & 4.22 & 0.06 & 0.14 & C. cassia \\
Paeonol & 8.77 & 0.09 & 0.10 & P. suffruticosa \\
\hline
\end{tabular}

${ }^{\mathrm{a} A}$ mount of each compound vs freerzed dried GJBRHE $\mathrm{g}$
500,1000 , or $2000 \mathrm{mg} / \mathrm{kg}$. The cytotoxicity indices, i.e. the $\mathrm{PCE} /(\mathrm{PCE}+\mathrm{NCE})$ ratios, were $0.59,0.53,0.55$, and 0.48 for the vehicle control (0), 500, 1000, and $2000 \mathrm{mg} /$ $\mathrm{kg} /$ day groups, respectively. The frequencies of micronucleated PCEs among 2000 PCEs were 1.67, 0.67, 0.33, and 0.67 for the vehicle control (0), 500, 1000, and $2000 \mathrm{mg} / \mathrm{kg} /$ day groups, respectively (Table 5). There was no significant increase in the frequencies of micronucleated PCEs at any dose level of GJBRHE. The positive control substance induced a significant increase in the ratio, to 54.33 compared with that of the vehicle controls $(P<0.01)$.

\section{Discussion}

GJBRHE comprises five herbs, Cinnamomum cassia, Poria cocos, Paeonia suffruticosa, Oaeonia lactiflora, and Prunus persica, in 1:1:1:1:1 proportions. The main medicinal constituents of each herb are as follows: amygdalin from $P$. persica [30], coumarin (e.g. cinnamic acid, coumarin, and cinnamaldehyde) from C. cassia [31, 32], monoterpenoids (e.g. paeoniflorin and albiflorin) from Pa. lactiflora [30] and cyanoglucosides (e.g. amygdalin) from Pr. Persica [30]. We analyzed seven of these compounds using HPLC-PDA: albiflorin (2.29 $\mathrm{mg} / \mathrm{g})$, amygdalin $(12.51 \mathrm{mg} / \mathrm{g})$, coumarin $(2.62 \mathrm{mg} / \mathrm{g})$, cinnamic acid $(0.52 \mathrm{mg} / \mathrm{g})$, cinnamaldehyde $(4.22 \mathrm{mg} / \mathrm{g})$, paeonol $(8.77 \mathrm{mg} / \mathrm{g})$, and paeoniflorin $(45.07 \mathrm{mg} / \mathrm{g})$. The established HPLC-PDA method was applied for simultaneous analysis of the seven compounds in GJBRHE and detected paeoniflorin (45.07 $\mathrm{mg} / \mathrm{g}$ ), a marker of $\mathrm{G}$. jasminoides, as the major component of GJBRHE.

Previous several studies have reported the pharmacological efficacy of Gyejibokryeong-hwan [10-15], but have not provided information about its safety. To evaluate some potential genotoxicities of GJBRHE, we performed an in vitro chromosomal aberration test, an in vitro Ames test, and an in vivo MN test. The results of the present study demonstrated that GJBRHE, a traditional Koran herbal medicine, was not genotoxic using an in vitro Ames test or an in vivo $\mathrm{MN}$ test, but genotoxicity was detected in an in vitro chromosomal aberration test.

The in vitro chromosome aberration test is used to identify structural chromosomal aberrations [20]. In present study, there were significant increases the number of metaphases with structural aberrations after treatment for $6 \mathrm{~h}$ with GJBRHE at $4200 \mu \mathrm{g} / \mathrm{mL}$ in the presence of the $S 9$ fraction and after treatment for $22 \mathrm{~h}$ with GJBRHE at $800 \mu \mathrm{g} / \mathrm{mL}$ without the S9 fraction. However, to confirm these results, more reliable tests are needed.

The Ames test was developed by Ames and coworkers in the early 1970s to assess the mutagenic potential and to estimate carcinogenic potential of environmental 


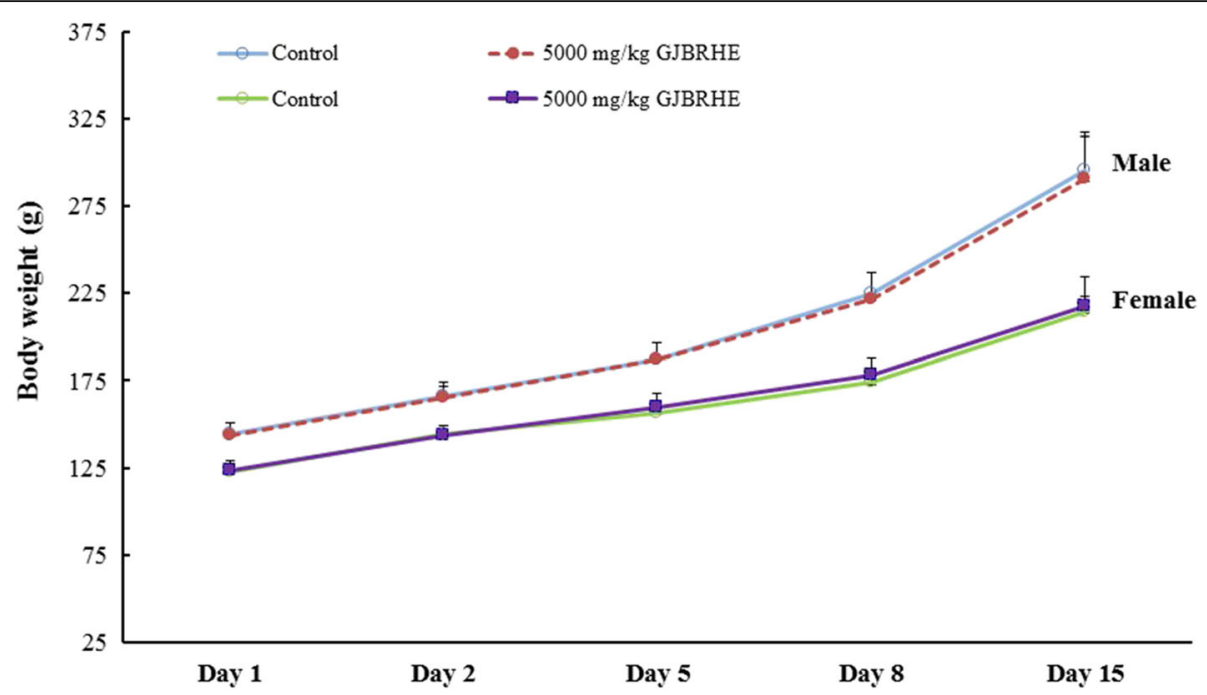

Fig. 2 Mean body weight changes after administration of GJBRHE
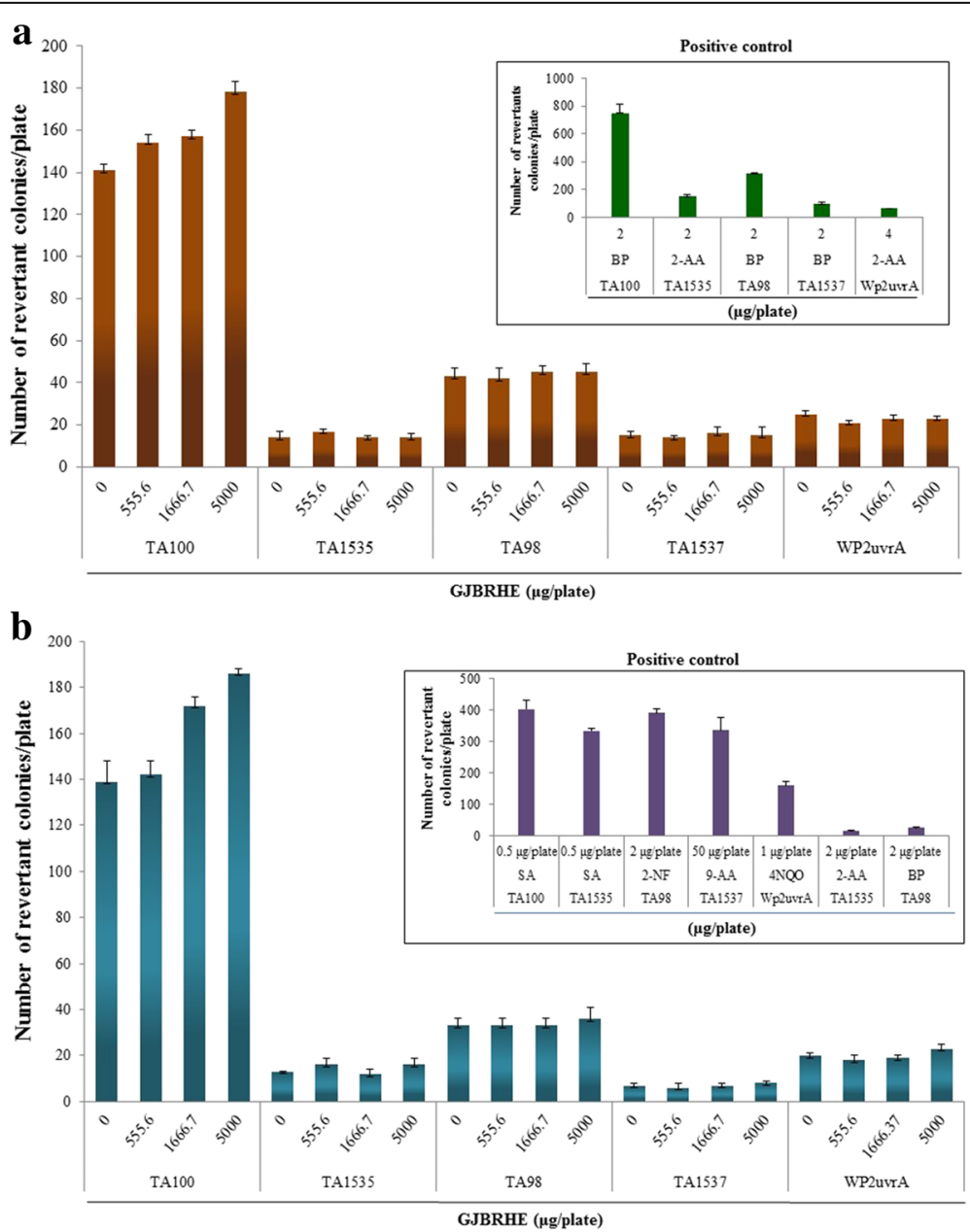

Fig. 3 Effects of GJBRHE in the bacterial reverse mutation assay (Ames test) (a) in the presence of (+S9 fraction) and (b) in the absence of (-S9 fraction) metabolic activation 
Table 3 Chromosome aberration assay and relative cell counts of Gyejibokryeong-hwan aqueous extract (GJBRHE)

\begin{tabular}{|c|c|c|c|c|c|c|}
\hline Nominal conc. of GJBRHE ( $\mu \mathrm{g} / \mathrm{mL})$ & S9 mix & Time hours & $\begin{array}{l}\text { Mean total aberrant } \\
\text { metaphases }\end{array}$ & $\begin{array}{l}\text { Mean total } \\
\text { aberrations }\end{array}$ & Mean of PP $+\mathrm{ER}$ & Relative cell counts $(\%$ \\
\hline \multicolumn{7}{|l|}{6 h treatment $(+59)$} \\
\hline 0 & + & $6-18$ & $1.0 / 0.5^{b)}$ & $1.0 / 0.5$ & $0.0+0.0$ & 100 \\
\hline 1050 \# & + & $6-18$ & $0.5 / 0.5$ & $0.5 / 0.5$ & $1.0+0.0$ & 98 \\
\hline $2100 \#$ & + & $6-18$ & $1.5 / 0.5$ & $1.5 / 0.5$ & $0.0+0.0$ & 80 \\
\hline $4200^{\# \S}$ & + & $6-18$ & $21.0 / 21.0^{* *}$ & $36.0 / 36.0$ & $1.5 / 0.0$ & 47 \\
\hline 4500 \#\$ & + & $6-18$ & & Not counted & & 43 \\
\hline CPA 6 & + & $6-18$ & $24.0 / 24.0^{* *}$ & $38.0 / 37.5$ & $0.5+0.0$ & 63 \\
\hline \multicolumn{7}{|l|}{6 h treatment $(-59)$} \\
\hline 0 & - & $6-18$ & $0.5 / 0.0$ & $0.5 / 0.0$ & $0.0+0.0$ & 100 \\
\hline 225 & - & $6-18$ & Not counted & & & 94 \\
\hline $450^{\# \S}$ & - & $6-18$ & $1.5 / 1.0$ & $1.5 / 1.0$ & $1.5+0.0$ & 80 \\
\hline 900 \#§ & - & $6-18$ & $1.0 / 1.0$ & $1.0 / 1.0$ & $0.0+0.0$ & 66 \\
\hline $1050^{\# \S}$ & - & $6-18$ & $2.0 / 0.5$ & $2.0 / 0.5$ & $1.0+0.0$ & 50 \\
\hline EMS 800 & - & $6-18$ & $25.5 / 25.0^{* *}$ & $37.0 / 36.0$ & $0.0+0.0$ & 58 \\
\hline \multicolumn{7}{|l|}{$22 \mathrm{~h}$ treatment (-\$9) } \\
\hline 0 & - & $22-2$ & $1.0 / 1.0$ & $2.0 / 2.0$ & $0.5+0.0$ & 100 \\
\hline 180 & - & $22-2$ & $1.5 / 1.0$ & $1.5 / 1.0$ & $0.0+0.0$ & 89 \\
\hline 360 \#\$ & - & $22-2$ & $2.5 / 1.5$ & $4.0 / 2.0$ & $0.5+0.0$ & 79 \\
\hline 720 \#§ & - & $22-2$ & Not counted & & & 66 \\
\hline $800^{\# \S}$ & - & $22-2$ & $7.5 / 6.5^{* *}$ & $9.5 / 7.5$ & $1.0+0.0$ & 48 \\
\hline EMS 600 & - & $22-2$ & $43.5 / 43.0^{* *}$ & $69.5 / 68.5$ & $0.0+0.0$ & 41 \\
\hline
\end{tabular}

"Visible turbidity of test item was observed at the beginning of treatment

${ }^{5}$ Visible turbidity of test item was observed at the end of the treatment

** Significantly different from the control at $P<0.01$

a) Treatment time-recovery time

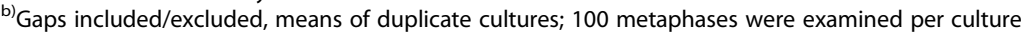

mixtures [33]. The Ames test uses strains of $S$. typhimurium TA100, TA98, TA1535, and TA1537 and the tryptophan auxotroph strain E. coli WP2 uvrA to detect point mutations involving substitution, addition, or deletion of one or more DNA base pairs [19]. The Ames test is commonly employed as an initial screen for genotoxicity, particularly point mutation induction activity. Mutation of genes results in a deficient DNA repair system and greatly enhances the sensitivity of these strains to certain mutagens [34]. There were no increases in the number of revertant colonies of S. typhimurium (TA100, TA 98, TA1535, and TA1537) and E. coli (WP2 uvrA) at any concentration $(5000,1666.7$, or $555.6 \mu \mathrm{g} / \mathrm{plate})$ of

Table 4 Body weight changes of Micronucleus test in mice following administration of Gyejibokryeong-hwan aqueous extract (GJBRHE)

\begin{tabular}{lllll}
\hline 0 & 500 & 1000 & 2000 & 70 \\
\hline $33.7 \pm 0.85$ & $34.2 \pm 1.07$ & $33.9 \pm 1.54$ & $34.0 \pm 1.07$ & $33.2 \pm 1.87$ \\
$34.3 \pm 0.66$ & $34.8 \pm 0.75$ & $34.0 \pm 1.39$ & $34.6 \pm 0.87$ & $34.8 \pm 1.82$ \\
$34.4 \pm 0.60$ & $35.0 \pm 0.81$ & $33.7 \pm 0.85$ & $34.8 \pm 1.82$ & $33.9 \pm 1.69$ \\
\hline
\end{tabular}

GJBRHE in the presence or absence of a metabolic system (S9 fraction). Our results indicate that under the conditions of this study, GJBRHE did not show mutagenicity in the Ames test. Therefore, GJBRHE did not appear to mutate any genes in vitro.

The MN test is useful for the detection of chemically induced chromosome damage [35]. In the present study, there was no significant or dose-related increase in the number of micronucleated PCEs per 2000 PCEs at any GJBRHE treatment dose level. In addition, no abnormal signs in the general appearance and body weight of mouse were observed in any of the GJBRHE treated groups. The $\mathrm{PCE} /(\mathrm{PCE}+\mathrm{NCE})$ ratio, an indicator of

Table 5 Results of micronucleus assay in male mice

\begin{tabular}{lllll}
\hline 0 & 500 & 1000 & 2000 & 70 \\
\hline $1.67 \pm 0.58$ & $0.67 \pm 1.15$ & $0.33 \pm 0.58$ & $0.67 \pm 1.15$ & $54.33 \pm 6.43$ \\
$0.59 \pm 0.09$ & $0.53 \pm 0.08$ & $0.55 \pm 0.09$ & $0.48 \pm 0.02$ & $0.47 \pm 0.05$ \\
3 & 3 & 3 & 3 & 3
\end{tabular}

MNPCE PCE with one or more micronuclei, PCE polychromatic erythrocyte, NCE normochromatic erythrocyte

Positive control: Cyclophosphamide Monohydrate 
cytotoxicity, was not significantly decreased compared with the vehicle control. An elevated frequency of micronucleated PCEs indicates chromosomal damage [36-38]. MN assay has revealed the accumulated genotoxic damage during the lifetime of the cells [39]. An increased MN frequency is related to cancer risk [40, 41].

\section{Conclusions}

GJBRHE did not cause detectable genotoxic effects in the bacterial mutation test or the in vivo MN test, however genotoxic effect was detected in the in vitro chromosomal aberration assay. Our results suggest that GJBRHE may be associated with a low risk of carcinogenesis. Thus, further detailed experiments would be needed to clarify the compound responsible for inducing this genotoxicity of GJBRHE and to determine its mechanism.

\section{Acknowledgments}

This research was part of a project (Construction of Scientific Evidence for Herbal Medicine Formulas) funded by the K-herb Research Group in the Korea Institute of Oriental Medicine.

\section{Availability of data materials}

The datasets supporting the conclusion of this article are included within the article.

\section{Funding}

This research was part of a project (Construction of Scientific Evidence for Herbal Medicine Formulas) funded by the K-herb Research Group in the Korea Institute of Oriental Medicine.

\section{Authors' contributions}

MYL, JYK, HKH and HKS participated in the design of the study, data analyses and manuscript preparation. CSS carried out the preparation of GJBRHE, HPLC analysis, and manuscript preparation. ESP participated in the manuscript revision process about data analyses. JYK conducted the genototoxicity examination in vitro and in vivo. All authors read and approved the final manuscript.

\section{Ethics approval and consent to participate}

The animal studies were conducted according to the guidance of the Institutional Animal Care and Use Committee in the Korea Institute of Toxicology (KRICT) (accredited by AAALAC International, 1998) under the current Good Laboratory Practice regulations for nonclinical laboratory studies.

\section{Consent for publication}

Not applicable.

\section{Competing interests}

The authors declare that they have no competing interests.

\section{Publisher's Note}

Springer Nature remains neutral with regard to jurisdictional claims in published maps and institutional affiliations.

\section{Author details}

${ }^{1} \mathrm{~K}$-herb Research Center, Korea Institute of Oriental Medicine, 1672 Yuseongdae-ro, Yuseong-gu, Daejeon 305-811, Republic of Korea. ${ }^{2}$ Division of Nonclinical Studies, Korea Institute of Toxicology, P.O. Box 123, 19 Sinseongro, Yuseong-gu, Daejeon 305-343, Republic of Korea.
Received: 12 April 2017 Accepted: 7 December 2017

Published online: 22 January 2018

\section{References}

1. Lynch N, Berry C. Differences in perceived risks and benefits of herbal, over-the-counter conventional, and prescribed conventional, medicines, and the implications of this for the safe and effective use of herbal products. Compl Ther Med. 2007;15:84-91.

2. Jordan SA, Cunningham DJ, Marles RJ. Assessment of herbal medicinal products: challenges, and opportunities to increase the knowledge base for safety assessment. Toxicol Appl Pharmacol. 2010;243:198-216.

3. Seeff LB. Herbal hepatotoxicity. Clin Liver Dis. 2007;11:577-96.

4. Lee SK, Kim HG, Ahan JC, Chung TW, Moon JY, Park SD, et al. Effect of the Geijibokryunghwan on human hepatocarcinoma cells. Kor J Orient Physiol Pathol. 2003;17:568-73.

5. Firenzuoli F, Gori L. Herbal medicine today: clinical and research issues. Evid Based Complement Alternat Med. 2007:4:37-40.

6. Rousseaux CG, Schachter $\mathrm{H}$. Regulatory issues concerning the safety, efficacy and quality of herbal remedies. Birth Defects Res B Dev Reprod Toxicol. 2003:68:505-10.

7. Madle S, Korte A, Ball R. Experience with mutagenicity testing of new drugs: view point of a regulatory agency. Mutat Res. 1987;182:187-92.

8. Professor association of herbal formula of Korea medicine. Herbal formula. Seoul: Youngrimsa; 2003. p. 409.

9. Western Pacific region of the World Health Organization. WHO international standard terminologies on traditional medicine in the western pacific region: World Health Organization; 2007. p. 186.

10. Jeong SJ, Lim HS, Seo CS, Jin SE, Yoo SR, Lee N, et al. Anti-inflammatory actions of herbal formula Gyejibokryeong-hwan regulated by inhibiting chemokine production and STAT1 activation in HaCaT cells. Biol Pharm Bull. 2015;38:425-34

11. Kim BJ, Kim YK, Park WH, Ko JH, Lee YC, Kim CH. A water-extract of the Korean traditional formulation Geiji-Bokryung-Hwan reduces atherosclerosis and hypercholesteremia in cholesterol-fed rabbits. Int Immunopharmacol. 2003:3:723-34

12. Goto M, Shimada Y, Sekiya N, Yang Q, Kogure T, Mantani N, et al. Effects of Keishi-bukuryo-gan on vascular function and hemorheological factors in spontaneously diabetic (WBN/kob) rats. Phytomedicine. 2004;11:188-95.

13. Nakagawa T, Yokozawa T, Terasawa K, Nakanishi K. Therapeutic usefulness of Keishi-bukuryo-gan for diabetic nephropathy. J Pharm Pharmacol. 2003;55: 219-27.

14. Shimada Y, Yokoyama K, Goto H, Sekiya N, Mantani N, Tahara E, et al. Protective effect of keishi-bukuryo-gan and its constituent medicinal plants against nitric oxide donor-induced neuronal death in cultured cerebellar granule cells. Phytomedicine. 2004;11:404-10.

15. Yao Z, Shulan Z. Inhibition effect of Guizhi-Fuling-decoction on the invasion of human cervical cancer. J Ethnopharmacol. 2008;120:25-35.

16. Demma J, Engidawork E, Hellman B. Potential genotoxicity of plant extracts used in Ethiopian traditional medicine. J Ethnopharmcol. 2009;122:136-42.

17. Lee MY, Seo CS, Kim JY, Shin HK. Evaluation of a water extract of soCheong-Ryong-tang for acute toxicity and genotoxicity using in vitro and in vivo tests. BMC Complement Altern Med. 2015;15:235.

18. OECD (1997): Principles of good laboratory practice.

19. Maron DM, Ames BN. Revised methods for the salmonella mutagenicity test. Mutat Res. 1983;113:173-215.

20. Ishidate M Jr, Sofuni T. The in vitro chromosomal aberration test using Chinese hamster lung (CHL) fibroblast cells in culture. Pro Mutat Res. 1985;5: 427-32.

21. Dean BJ, Danford N. Assays for the detection of chemically-induced chromosome damage in cultured mammalian cells. In: Venitt S, Parry JM, editors. Mutagenicity testing - a practical approach IRL limited. Eynsham; 1984. p. 197-232.

22. Muangphra P, Gooneratne R. Comparative genotoxicity of cadmium and lead in earthworm coelomocytes. Appl Environ Soil Sci. 2011;2011:1-7.

23. Schmid W. The microncleus test. Mutat Res. 1975:31:9-15.

24. Shin IS, Seo CS, Ha HK, Lee MY, Huang DS, Huh Jl, et al. Genotoxicity assessment of Pyungwi-san (PWS), a traditional herbal prescription. J Ethnopharmacol. 2011;133:696-703.

25. Richardson C, Williams DA, Allen JA, Amphlett G, Chanter DO, Phillips B. Analysis of data from in vitro cytogenetics assays. In: Kirland DJ, editor. 
Statistical evaluation of mutagenicity test data. Campridge UK: Camridge University Press; 1989. p. 141-54.

26. Fisher RA. Statistical methods for research workers. 14. Edinburgh: Oliver and Boyd; 1970.

27. Lee MY, Seo CS, Kim JY, Shin HK. Genotoxicity evaluation of Guibi-tang extract using an in vitro bacterial reverse mutation assay, chromosome aberration assay, and in vivo micronucleus test. BMC Complement Altern Med. 2014;14:215.

28. Lovell DP, Anderson D, Albanese R, Amphlett GE, Clare G, Ferguson R, et al. Statistical analysis on in vivo cytogenetic assays. In: Kirkland DJ, editor. Statistical evaluation of Mutagenicity test data. UKEMS sub-committee on guidelines for Mutagenicity testing, report, part Ш. New York: Cambridge University Press; 1989. p. 184-232.

29. Kruskal WH, Wallis WA. Use of ranks in one criterion variance analysis. J Am Stat Assoc. 1952:47:614-7.

30. Korean Pharmacopoeia Committee. The Korean pharmacopoeia, 10th, Shinikbooks; 2013. p. 1129-92.

31. Liang K, Cui S, Zhang Q, Bi K, Qian Z, Jia Y. UPLC simultaneous determination of five active components in Cinnamomi Ramulus. Zhongguo Zhong Yao Za Zhi. 2011;36:3298-301.

32. Wen KC, Huang CY, Liu FS. Determination of cinnamic acid and paeoniflorin in traditional Chinese medicinal preparations by high-performance liquid chromatography. J Chromatogr. 1992;593:191-9.

33. Shin KY, Won BY, Ha HJ, Yun YS, Lee HG. Genotoxicity studies on the root extract of Polygala tenuifolia Willdenow. Regul Toxicol Pharmacol. 2015;71: $365-70$.

34. Cho JS, Cheon EJ, Kim TU, Moon WS, Kim JW, Kim MR. Genotoxicity of rice bran oil extracted by supercritical CO2 extraction. Biol Pharm Bull. 2014;37: 1963-70.

35. Ashby J. Is there a continuing role for the intraperitoneal injection route of exposure in short-term rodent genotoxicity assays. Mutat Res. 1985;156:239-43.

36. Fenech M, Holland N, Chang WP, Zeiger E, Bonassi S. The HUman MicroNucleus project-an international collaborative study on the use of the micronucleus technique for measuring DNA damage in humans. Mutat Res. 1999:428:271-83.

37. Fenech M. The in vitro micronucleus technique. Mutat Res. 2000;455:81-95.

38. Fenech M. Cytokinesis-block micronucleus cytome assay. Nat Protoc. 2007;2: 1084-104.

39. Bolognesi C, Hayashi M. Micronucleus assay in aquatic animals. Mutagenesis. 2011;26:205-13.

40. Bonassi S, Znaor A, Ceppi M, Lando C, Chang WP, Holland N, et al. An increased micronucleus frequency in peripheral blood lymphocytes predicts the risk of cancer in humans. Carcinogenesis. 2006;28:625-31.

41. Murgia E, Ballardin M, Bonassi S, Rossi AM, Barale R. Validation of micronuclei frequency in peripheral blood lymphocytes as early cancer risk biomarker in a nested case-control study. Mutat Res. 2008;639:27-34.

\section{Submit your next manuscript to BioMed Central and we will help you at every step:}

- We accept pre-submission inquiries

- Our selector tool helps you to find the most relevant journal

- We provide round the clock customer support

- Convenient online submission

- Thorough peer review

- Inclusion in PubMed and all major indexing services

- Maximum visibility for your research

Submit your manuscript at www.biomedcentral.com/submit

) Biomed Central 